\title{
Study on coupling of new urbanization and environmental quality in Qinghai Province
}

\author{
Zhenhua Shao*, Yun Li, and Shengxi Ding \\ Qinghai University School of Finance and Economics; Xining, Qinghai 810016
}

\begin{abstract}
This paper selects the index data of population, economy and space from 2000 to 2019, establishes an evaluation index system for the level of new urbanization and environmental quality in Qinghai Province, studies the coordination between new urbanization and environmental quality in Qinghai Province by establishing a coupling coordination model, and puts forward countermeasures and suggestions for the coordinated development of new urbanization and environmental quality in Qinghai Province.
\end{abstract}

Keywords: New urbanization; Environmental quality; Coupling coordination.

\section{Introduction}

China has a population of nearly 1.4 billion, with a large proportion of rural population, large gap between urban and rural areas and regions, irrational economic development structure, and urbanization is an inevitable choice.Grossman and Kruger (1995) used econometric methods to conduct empirical research and put forward the famous Environmental Kuznets Curve Hypothesis (EKC) [1]. Liu Yaobin et al. (2005) quantitatively revealed the main factors of the coupling between urbanization and ecological environment system in various provinces of China [2]. There is little research on the relationship between new urbanization and environment in Northwest China, especially Qinghai Province, which is also the significance and innovation of this paper.Urbanization has many rich connotations. New urbanization is people-oriented, establishing modern civilization and realizing the goal of common prosperity [3].

\section{Overview of new urbanization level and environmental quality in Qinghai Province}

\subsection{Development status of new urbanization in Qinghai Province}

Population urbanization change: The urbanization level of Qinghai Province has an obvious upward trend from 1996 to 2019. Economic urbanization changes: In 2019, the per capita GDP of Qinghai Province increased to 48,981 yuan. Spatial urbanization change: the

\footnotetext{
*Corresponding author: 2558769265@qq.com
} 
construction land area of Qinghai Province is 202.43 square kilometers in 2019.

\subsection{Dynamic changes of environmental quality in Qinghai Province}

Environmental pollution control: In the past 19 years, the sewage treatment rate in Qinghai Province has increased by 11.51 times and the utilization rate of industrial solid waste has increased by 3.66 times. Energy consumption: From 2000 to 2019, the total energy consumption in Qinghai Province increased as a whole.

\section{Coupling analysis of new urbanization construction and environmental quality in Qinghai Province}

\subsection{Regression analysis}

It is of economic significance to use Eviews software to regress the new urbanization and environmental quality in Qinghai Province. Taking the comprehensive score of new urbanization as independent variable and the comprehensive score of environmental quality as dependent variable (Table 1), it is found that there is a cubic functional relationship between them, and a regression model is established:

Table 1. Comprehensive score of urbanization level and environmental quality in each year.

\begin{tabular}{|c|c|c|}
\hline age & $\begin{array}{c}\text { Comprehensive score of } \\
\text { urbanization level }\end{array}$ & $\begin{array}{c}\text { Comprehensive score of } \\
\text { environmental quality }\end{array}$ \\
\hline 2000 & -0.038 & 0.146 \\
\hline 2001 & -0.001 & 0.329 \\
\hline 2002 & 0.027 & 0.171 \\
\hline 2003 & 0.068 & -0.047 \\
\hline 2004 & 0.097 & -0.089 \\
\hline 2005 & 0.127 & -0.03 \\
\hline 2006 & 0.19 & 0.057 \\
\hline 2007 & 0.227 & 0.159 \\
\hline 2008 & 0.301 & 0.253 \\
\hline 2009 & 0.354 & 0.441 \\
\hline 2010 & 0.418 & 0.451 \\
\hline 2011 & 0.507 & 0.644 \\
\hline 2012 & 0.554 & 0.606 \\
\hline 2013 & 0.577 & 0.637 \\
\hline 2014 & 0.63 & 0.675 \\
\hline 2015 & 0.601 & 0.606 \\
\hline 2016 & 0.623 & 0.624 \\
\hline 2017 & 0.645 & 0.657 \\
\hline 2018 & 0.657 & 0.693 \\
\hline 2019 & 0.681 & 0.635 \\
\hline
\end{tabular}

Data source: Qinghai Statistics Bureau

$$
Y=\beta 0+\beta 1 X 3+\beta 2 X 2+\beta 3 X
$$

$$
\begin{gathered}
\mathrm{Y}=0.143712-13.58813+13.83677 \mathrm{X} 2-2.57712 \mathrm{X}(0.043566)(3.396949)(3.044518) \\
(0.708266)
\end{gathered}
$$

The adjusted determinable coefficient $\mathrm{R} 2=0.898485$ has high goodness of fit, which proves that there is a high correlation between them, The $\mathrm{T}$ values of constants $\mathrm{C}, \mathrm{X} 3, \mathrm{X} 2$ and $X$ are 3.298755, -4.000092, 4.544817 and -3.638626 , respectively, which have passed the test, and $F=45.25845$ is larger than the critical value. Through fitting diagram, it is 
found that there is an inverted "N" relationship between urbanization and environmental quality in Qinghai Province, which shows that environmental quality in Qinghai Province has been affected in the implementation of new urbanization(Figure1).

comprehensive score of environmental quality

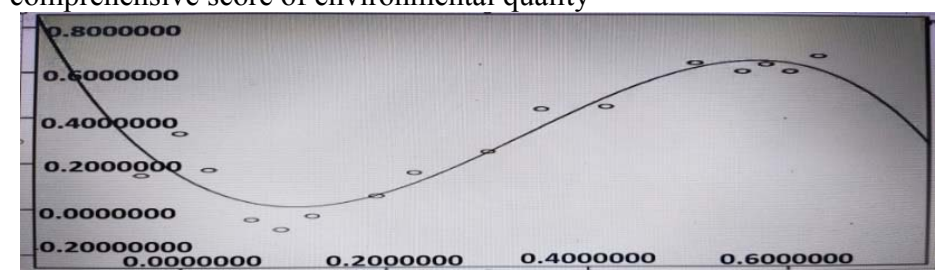

Comprehensive score of new urbanization

Fig. 1. Regression curve fitting diagram of urbanization and environmental quality in Qinghai Province.

\subsection{Coupling function}

The coupling function in physics is

$C n=n\{[U A(u 1) * U A(u 2) * \ldots \ldots U a(u n)] /(\pi \quad u a(u i)+u a(u j))\} 1 / n$, which can be simplified as

$$
C=2 *\{[F(x) * E(y)] /[(F(x)+E(y)) *(F(x)+E(y))]\} 1 / 2
$$

In which c represents coupling degree, and $\mathrm{F}(\mathrm{x})$ and $\mathrm{E}(\mathrm{y})$ respectively represent comprehensive index of urbanization level and comprehensive index of environmental quality. The coupling degree is between [0,1]. There are negative values in the comprehensive scores of urbanization and environmental quality in Qinghai province through factor analysis, so here we deal with the five negative values, which are as follows: $\mathrm{M}=\mathrm{F}(\mathrm{x})+\mathrm{g}(3)$, where $\mathrm{m}$ represents the positive comprehensive score, $\mathrm{F}(\mathrm{x})$ is the negative value in the comprehensive scores of new urbanization or environmental quality, and $\mathrm{g}$ represents a positive number as small as possible to make $\mathrm{F}(\mathrm{x})$ positive.

Table 2. Comprehensive score and coupling degree after processing.

\begin{tabular}{|c|c|c|c|}
\hline age & $\begin{array}{c}\text { Comprehensive score of } \\
\text { urbanization }\end{array}$ & $\begin{array}{l}\text { Comprehensive environmental } \\
\text { score }\end{array}$ & Coupling degree $\mathrm{c}$ \\
\hline 2000 & 0.002 & 0.146 & 0.217 \\
\hline 2001 & 0 & 0.329 & 0.015 \\
\hline 2002 & 0.027 & 0.171 & 0.686 \\
\hline 2003 & 0.068 & 0.003 & 0.414 \\
\hline 2004 & 0.097 & 0.001 & 0.146 \\
\hline 2005 & 0.127 & 0.001 & 0.127 \\
\hline 2006 & 0.19 & 0.057 & 0.844 \\
\hline 2007 & 0.227 & 0.159 & 0.984 \\
\hline 2008 & 0.301 & 0.253 & 0.996 \\
\hline 2009 & 0.354 & 0.441 & 0.994 \\
\hline 2010 & 0.418 & 0.451 & 0.999 \\
\hline 2011 & 0.507 & 0.644 & 0.993 \\
\hline 2012 & 0.554 & 0.606 & 0.999 \\
\hline 2013 & 0.577 & 0.637 & 0.999 \\
\hline 2014 & 0.63 & 0.675 & 0.999 \\
\hline 2015 & 0.601 & 0.606 & 1 \\
\hline 2016 & 0.595 & 0.587 & 0.995 \\
\hline 2017 & 0.657 & 0.637 & 0.993 \\
\hline 2018 & 0.684 & 0.662 & 0.999 \\
\hline 2019 & 0.713 & 0.702 & 0.999 \\
\hline
\end{tabular}

The coupling degree calculated according to formula (2) is shown in Table 2, and it is 
found that it can not accurately reflect the coordination degree of coupling between new urbanization and environmental quality in Qinghai Province, so the coupling coordination model is introduced:

$$
\begin{aligned}
& D=\left(C^{*} T\right)(1 / 2) \\
& T=\alpha F(x)+\beta E(y)
\end{aligned}
$$

In the formula, D stands for coupling coordination degree, which ranges from $[0,1], \mathrm{T}$ stands for comprehensive evaluation index of urbanization and environmental quality reflecting the overall contribution of urbanization and environmental quality, and $\alpha$ and $\beta$ respectively represent the weights of urbanization and environmental quality representatives,In Qinghai Province, urbanization and environmental quality are equally important, so $\alpha$ and $\beta$ each take 0.5 , and the division scope of coupling coordination degree is divided by scholars as follows [4]:

Table 3. Classification standard of coupling coordination degree.

\begin{tabular}{cc}
\hline Coupling coordination degree (D) & Degree of coordination \\
\hline $0-0.09$ & Extreme imbalance \\
$0.10-0.19$ & Serious maladjustment \\
$0.20-0.29$ & Moderate maladjustment \\
$0.30-0.39$ & Mild maladjustment \\
$0.40-0.49$ & On the verge of disorder \\
$0.50-0.59$ & Reluctantly coordinate \\
$0.60-0.69$ & Primary coordination \\
$0.70-0.79$ & Intermediate coordination \\
$0.80-0.89$ & Good coordination \\
$0.90-1.00$ & Quality coordination \\
\hline
\end{tabular}

\subsection{Research conclusion of coupling between new urbanization and environmental quality in Qinghai Province}

According to the coupling degree model and coupling coordination degree model, the following table is obtained:

Table 4. Coupling coordination degree and grade of urbanization and environmental quality in

Qinghai Province.

\begin{tabular}{|c|c|c|c|}
\hline year & Comprehensive index t & $\begin{array}{c}\text { Coupling coordination } \\
\text { degree d }\end{array}$ & $\begin{array}{c}\text { Coupling coordination } \\
\text { level }\end{array}$ \\
\hline 2000 & 0.074 & 0.127 & Serious maladjustment \\
\hline 2001 & 0.164 & 0.05 & Extreme imbalance \\
\hline 2002 & 0.099 & 0.26 & Moderate aladjustment \\
\hline 2003 & 0.036 & 0.122 & Serious maladjustment \\
\hline 2004 & 0.049 & 0.084 & Extreme imbalance \\
\hline 2005 & 0.064 & 0.09 & Extreme imbalance \\
\hline 2006 & 0.124 & 0.323 & Mild maladjustment \\
\hline 2007 & 0.193 & 0.436 & On the verge of disorder \\
\hline 2008 & 0.277 & 0.525 & Reluctantly coordinate \\
\hline 2009 & 0.397 & 0.628 & Primary coordination \\
\hline 2010 & 0.435 & 0.659 & Primary coordination \\
\hline 2011 & 0.575 & 0.756 & Intermediate ordination \\
\hline 2012 & 0.58 & 0.761 & Intermediate ordination \\
\hline 2013 & 0.607 & 0.779 & Intermediate ordination \\
\hline 2014 & 0.652 & 0.808 & Good coordination \\
\hline 2015 & 0.604 & 0.777 & Intermediate ordination \\
\hline 2016 & 0.643 & 0.813 & Good coordination \\
\hline 2017 & 0.675 & 0.834 & Good coordination \\
\hline 2018 & 0.712 & 0.857 & Good coordination \\
\hline 2019 & 0.671 & 0.783 & Intermediate ordination \\
\hline
\end{tabular}


It can be seen from Table 4 that from 2000 to 2019, the coupling coordination between new urbanization and environmental quality in Qinghai Province fluctuated horizontally. Generally speaking, there is still much room for improvement in urbanization and environmental system in Qinghai Province.

\section{Countermeasures and suggestions on coordinated development of new urbanization and environmental Quality in Qinghai Province}

1.Optimize industrial structure 2. Increase investment in science and technology 3. Increase investment in environmental protection. This paper analyzes the environmental quality and urbanization in Qinghai Province in detail, which plays an important role in the development of economy, society and environmental quality in Qinghai Province.

\section{Acknowledgement}

Author brief introduction: Zhenhua Shao(1996-), male, kaifeng, Henan Province, master's degree, research interests: regional economy and sustainable development.

Correspondence author: Shengxi Ding (1971-), female, born in Xining, Qinghai, professor, master, research direction: regional economic development and urbanization.

Fund Project: National Social Science Fund Project: Research on Dynamic Mechanism and Path Selection of Green Development in Qaidam Basin (19BMZ154).

\section{References}

1. Grossman G, Kru Eger A. Economic growth and the environment[J]. Quarterly Journal of Economics, 1995(02):353-377.

2. Liu Yaobin et al,Correlation analysis of coupling between urbanization and ecological environment in China [J],Journal of Geography, 2005 (02): 237-247 .

3. Mao Xueyan et al. Empirical Study on Influencing Factors of New Urbanization in Qinghai Province [J],Northwest Population, 2014(06).

4. Liao Chongbin. Quantitative evaluation and classification system of coordinated development of environment and economy [J],Guangzhou Environmental Science, 1996, 11(01). 